\title{
The Scientific Assessment and Strategy Team
}

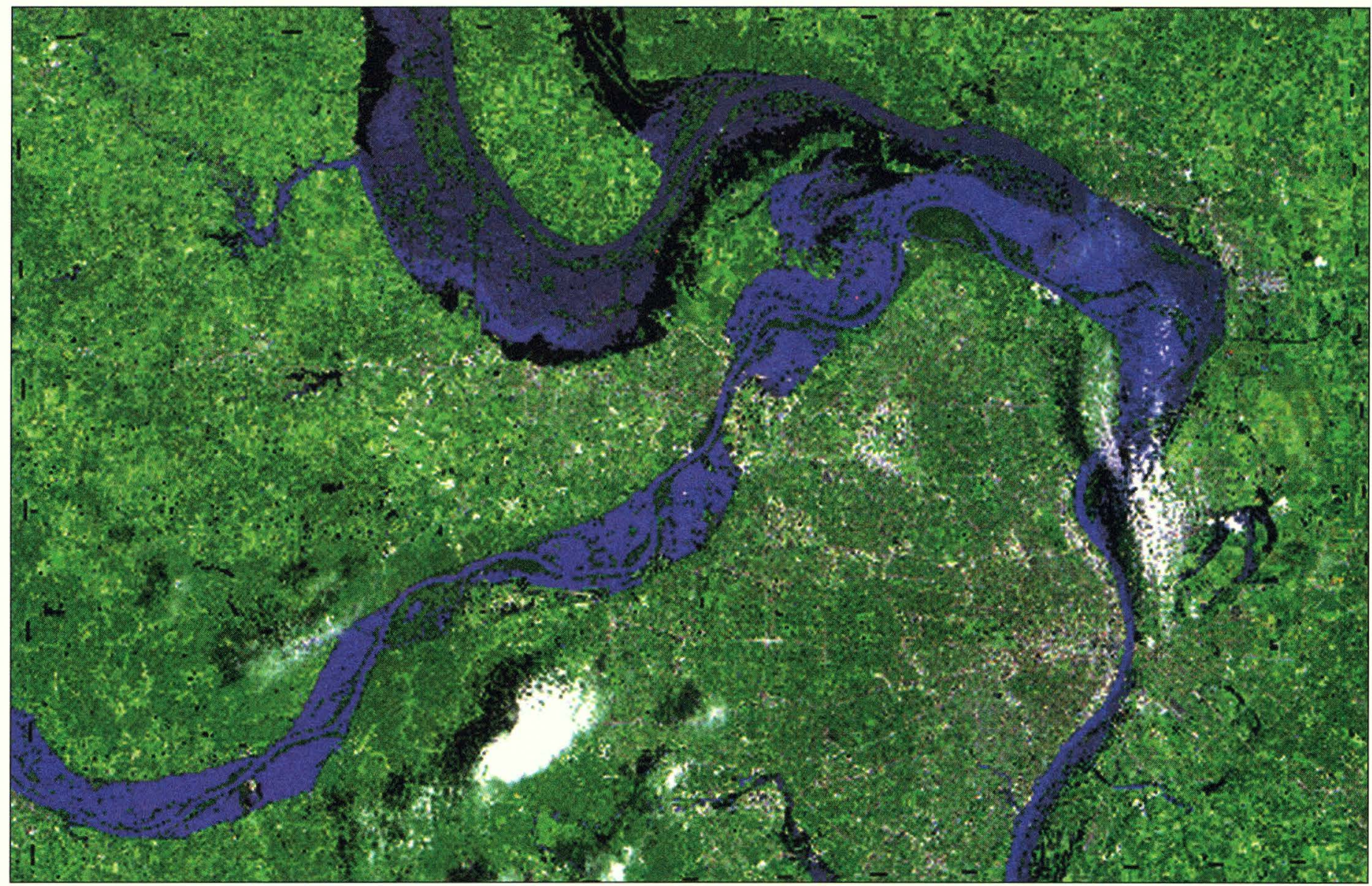

Landsat TM image showing near maximum stage of the 1993 flood peak at St. Louis, Missouri. Dark blue delineates areas of water.

The flood of 1993 in the Upper Mississippi River Basin caused widespread devastation. The human and economic costs were high. The total flood and other related damage estimates were in the $\$ 10$ billion to $\$ 16$ billion range, with total Federal expenditures in excess of $\$ 5.4$ billion. In response to the effects of the flood of 1993, the White House established the Scientific Assessment and Strategy Team (SAST) on November 24, 1993. The SAST's goals are to provide scientific advice and assistance to policymakers and officials responsible for flood recovery and river basin management in the Upper Mississippi River Basin and to prepare a data base to support those goals.

\section{Interagency Participation}

The SAST exemplifies how Federal agencies can work together to accomplish national goals. The SAST is an interdisciplinary team of senior scientists and engineers from the Department of Agriculture (Natural Resources Conservation Service), Department of Defense (U.S. Army Corps of Engineers), Department of the Interior (U.S. Fish and Wildlife, National Biological Service, and U.S. Geological Survey), Environmental Protection Agency, Federal Emergency Management Agency (FEMA), and Department of Commerce (National Weather Service). Initial funding was provided by FEMA and additional funding was provided through two supplemental appropriations to the U.S. Geological Survey (USGS). Critical assistance was also provided by State Government and nongovernment organizations.

\section{EROS Data Center Hosts Initial Phase of SAST}

The SAST received indepth technical and scientific support from the USGS Earth Resources Observation Systems (EROS) Data Center (EDC) in Sioux Falls, S. Dak., and met at the EDC for an initial workshop during December 1993 to identify the scope of the problem and to begin to address the many logistical 


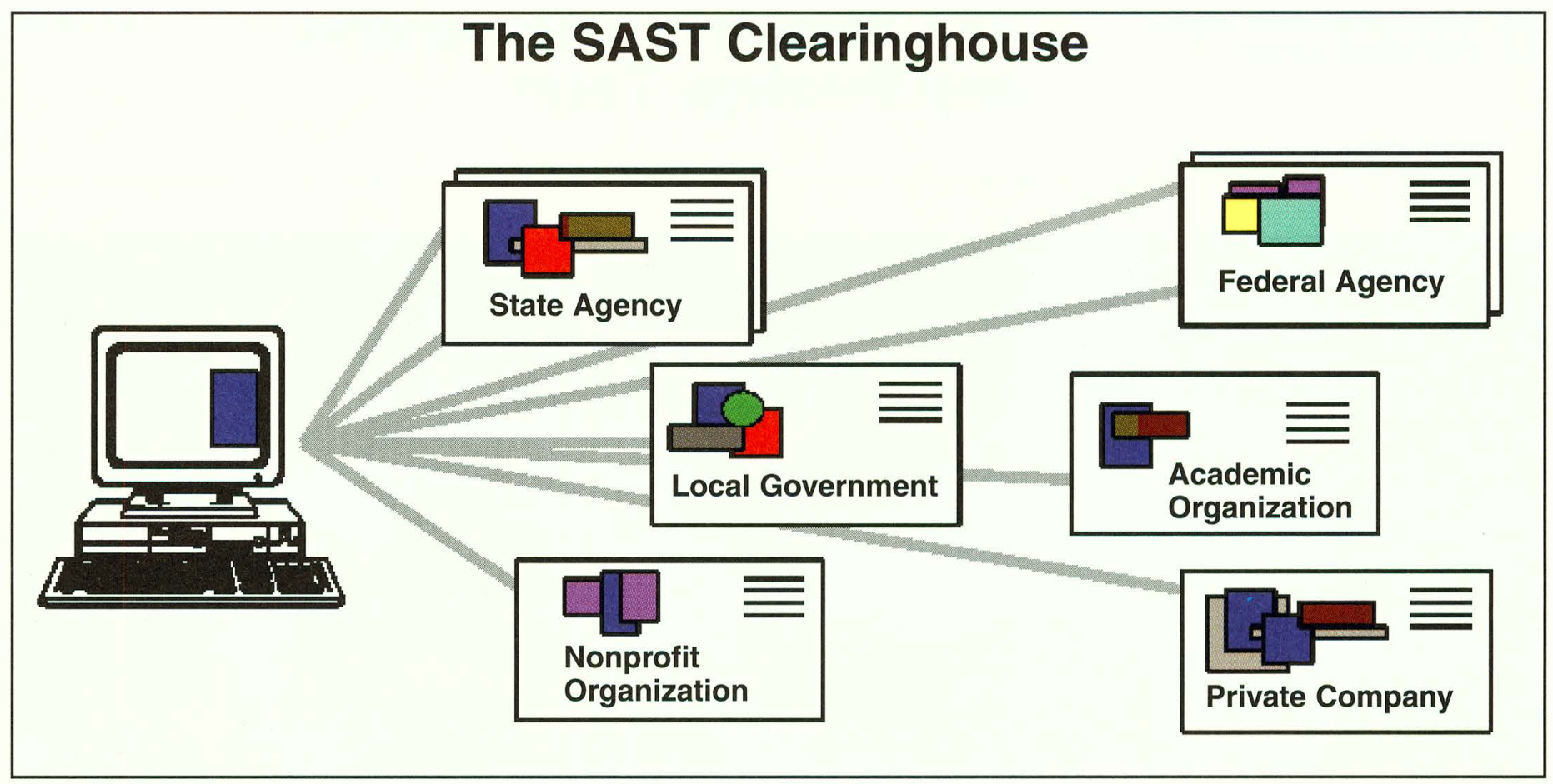

The SAST Clearinghouse meets the specifications of the Federal Geographic Data Committee. Both Federal and non-Federal organizations are responsible for maintaining and distributing data to the user community.

issues that the team would encounter. Beginning in early January 1994, the SAST spent a concentrated 10-week period at the EDC when most of the 250 gigabytes of data in the SAST Upper Mississippi data base were compiled. Since March 1994, the SAST continues to function as a distributed team with members working at their home offices or laboratories. The team, either as a group or its specific members, also conducts workshops to address various issues.

\section{The SAST Upper Mississippi River Data Base}

While at the EDC, the SAST built a multiresolution data base covering the geographic extent of the Upper Mississippi River Basin. The most concentrated and complete data are along the floodplains of the upper Mississippi and lower Missouri Rivers. These floodplains represent the areas of greatest interest to policymakers responsible for reacting to the 1993 flood, maintaining the Federal levee system, and restoring habitat. The data base contains advanced very high resolution radiometer, Landsat thematic mapper, and other satellite data; elevation data; selected digitized photographs; historical channel geometries; synthetic structures; geologic, biologic, hydrologic, hydrographic, soil survey, hazardous, and toxic data; and data on many other topics.

\section{Internet Access to the SAST Data Base}

Primary access to the data base is through the Internet using the Mosaic browser, which can access data in World Wide Web servers. This allows immediate access to the most current versions of the individual data layers and associated documentation, such as spatial metadata and related publications. For users who do not have Internet access, selected data sets will be made available on digital media by contacting:

Customer Services

U.S. Geological Survey

EROS Data Center

Sioux Falls, SD 57198

Telephone: 605-594-6151

Mosaic users can access the SAST data from the following URL:

http://edcwww.cr.usgs.gov/sast-home.html

\section{The SAST Distributed Clearinghouse for Data and Information}

Data maintenance, management, and distribution primarily use the distributed clearinghouse model. The SAST clearinghouse serves as a prototype for the Federal Geographic Data Committee and helps promote the National Spatial Data Infrastructure and the National Information Infrastructure. The EDC acts as the central node of the SAST clearinghouse. Other Federal, State, local, and tribal governments and nongovernment organizations act as nodes on the system. Each node is responsible for maintaining and distributing its own data to the user community. The EDC assists other organizations in designing mechanisms to meet quality assurance, documentation, data comparability, and distribution requirements.

\section{Floodplain and River Basin Management}

The data and information that the SAST has provided to policymakers and floodplain managers will assist them in recovery and restoration from the flood 
of 1993 and allow them to establish effective river basin and floodplain management practices for preventing or lessening the effects of future floods. The SAST recommends that these management techniques incorporate the needs of both the natural ecosystem and human activity. The analysis, results, and recommendations of the SAST have influenced long-term policy on many issues in the Upper Mississippi River Basin. The SAST serves as an example of a comprehensive Federal approach to planning and emergency preparedness.

\section{Major Accomplishments and Activities}

- Analysis of preliminary flood insurance payment data in the SAST data base revealed that many of the claims were made by people who had only recently purchased flood insurance, some as late as 5 days before the flood. This type of information was critical to helping decisionmakers pass congressional legislation (Riegle Community Development and Regulatory Improvement Act of 1994, PL 103-325) to extend the waiting period to 30 days. This change will save the Flood Insurance Program millions of dollars while still providing coverage to program participants.

- Parts of the SAST data base were used to help find suitable sites to relocate the entire town of Valmeyer, Ill., from the floodplain to the uplands. Valmeyer was almost entirely destroyed in the floods of 1993.

- The SAST data base is used to delineate priority habitat areas for restoration. The U.S. Fish and Wildlife Service and the State of Missouri have used these data extensively to identify and purchase land of high natural habitat value. A large parcel of land has already been purchased as part of the Big Muddy Wildlife Refuge.

- The SAST and the U.S. Army Corps of Engineers are cooperating to collect high-resolution, accurate digital elevation models along parts of the floodplains of the upper Mississippi, lower Missouri, and Illinois Rivers. These data are

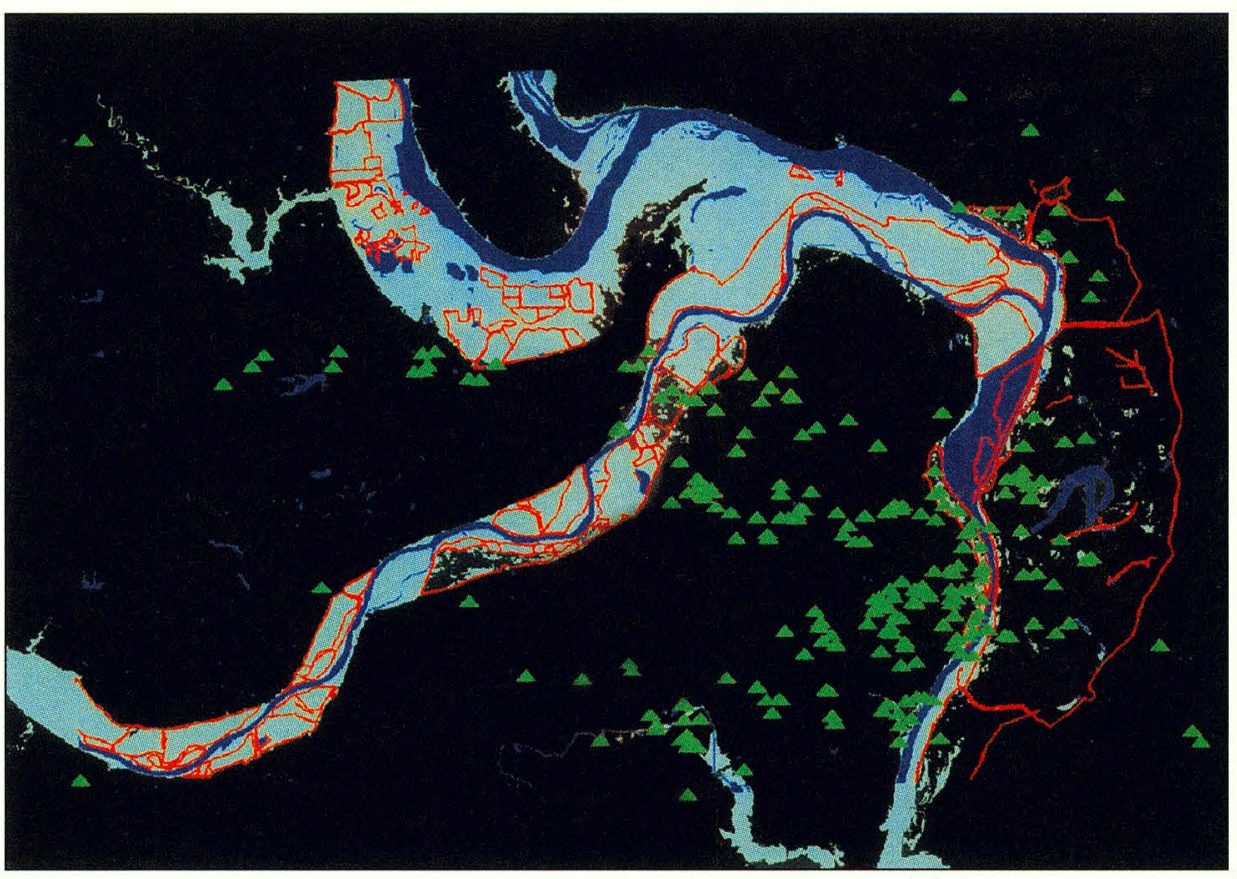

Computer-generated geographic information system image of the St. Louis 1:100,000-scale quadrangle. Orange designates levees and green triangles show toxic release inventory sites. Light blue shows the flood extent in 1993

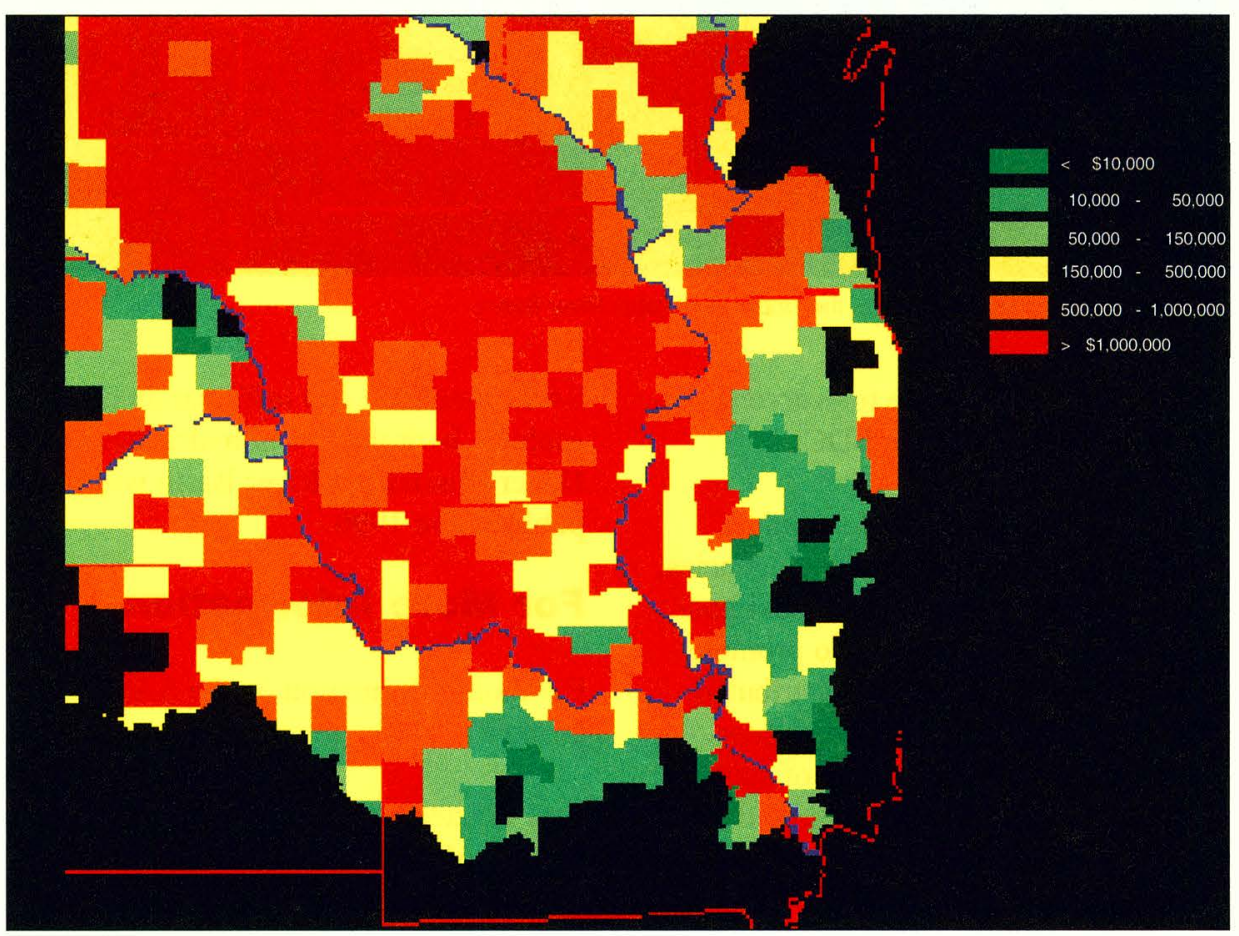

Crop disaster payments by county in the Upper Mississippi River Basin. Red areas show greatest dollar payment amounts.

extremely important for inclusion in hydraulic models, which will serve to protect the populations along these major rivers and the critical infrastructure in areas of the floodplain.

- Studies of land surface and biologic processes on the floodplain have enabled decisionmakers to reassess the economic use of these areas by identifying highrisk zones on the floodplain and high value habitat restoration sites.

- The SAST produced high-quality map products both on paper and in digital form of various data included in the SAST data base. This information is maintained through the SAST clearing- 


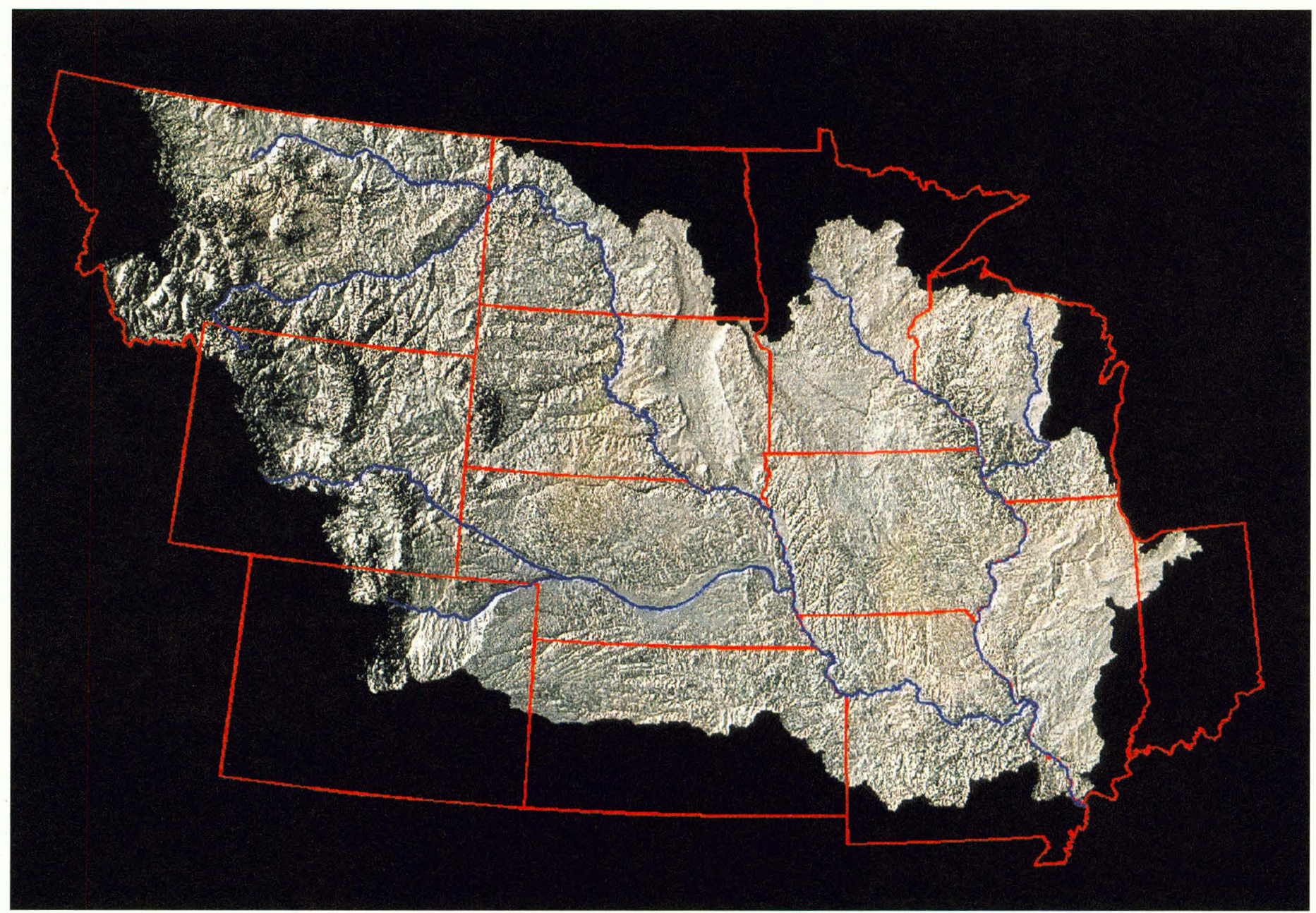

Shaded topographic relief map of the Upper Mississippi River Basin.

house and is accessible to everyone via the Internet or from the EDC.

- The SAST continues to conduct workshops with other Federal agencies, State and local governments, and nongovernment organizations to promote participation in the SAST distributed clearinghouse. The SAST data base contains data from a variety of sources. Management of the data will be the responsibility of the Federal or nonFederal organization that owns a particular data set.

- The SAST published a document of its activities and recommendations in November 1994. The publication, "A Blueprint for Change, Part V, Science for Floodplain Management into the 21st Century" (Book No. 040-000-00650-8), can be obtained from the Government Printing Office in Washington, D.C. Four additional documents describing the
SAST data base and information on the ecology, hydrology, and hydraulics of the Upper Mississippi River Basin will be published in 1996.

\section{For More Information}

For more information on the SAST, contact:

\section{Ann Frazier}

U.S. Geological Survey

521 National Center

Reston, VA 22092

703-648-4644; Fax 703-648-4165

E-mail: afrazier@usgs.gov

John Kelmelis

U.S. Geological Survey

519 National Center

Reston, VA 22092

703-648-4792; Fax 703-648-5542

E-mail: jkelmeli@usgs.gov
For information on other USGS products and services, contact any Earth Science Information Center (ESIC), call 1-800USA-MAPS, fax 703-648-5548, or e-mail: esicmail@usgs.gov.

The EARTHFAX fax-on-demand system is available 24 hours a day, at 703-6484888 .

The address for the USGS home page is: <URL: http://www.usgs.gov/> 